\title{
BMJ Open Sudden infant death syndrome (SIDS) and the routine otoacoustic emission infant hearing screening test: an epidemiological retrospective case- control study
}

\author{
Peter S Blair, ${ }^{1}$ Daniel Rubens, ${ }^{2}$ Anna Pease, ${ }^{1}$ Diane Mellers, ${ }^{3}$ Jenny Ingram, ${ }^{1}$ \\ Andrew K Ewer, ${ }^{4}$ Marta C Cohen, ${ }^{\circ}$ Peter Sidebotham, ${ }^{6}$ Martin Ward Platt, ${ }^{7}$ \\ Robert Coombs, ${ }^{8}$ Adrian Davis, ${ }^{9}$ Amanda Hall, ${ }^{10}$ Peter Fleming ${ }^{1}$
}

To cite: Blair PS, Rubens D, Pease A, et al. Sudden infant death syndrome (SIDS) and the routine otoacoustic emission infant hearing screening test: an epidemiological retrospective case-control study. BMJ Open 2019;9:e030026. doi:10.1136/ bmjopen-2019-030026

- Prepublication history for this paper is available online. To view these files, please visit the journal online (http://dx.doi. org/10.1136/bmjopen-2019 030026).

Received 23 February 2019 Revised 25 April 2019 Accepted 22 May 2019
Check for updates

(C) Author(s) (or their employer(s)) 2019. Re-use permitted under CC BY-NC. No commercial re-use. See rights and permissions. Published by BMJ.

For numbered affiliations see end of article.

Correspondence to

Dr Peter S Blair;

p.s.blair@bris.ac.uk

\section{ABSTRACT}

Objectives To investigate whether decreased otoacoustic emission (OAE) signal recordings in the right ear are associated with an increased risk of sudden infant death syndrome (SIDS) and to monitor any temporal changes in risk factors.

Design Retrospective case-control study.

Setting Telephone interviews with families recruited in England between July 2016 and October 2017 who experienced the unexpected death of a child $<4$ years old since 2008 and control families recruited from maternity wards in Bristol and Birmingham.

Participants We recruited 91 (89\%) of the 102 bereaved families who made initial contact, 64 deaths were under 1 year (sudden unexpected death in infancy) of which 60 remained unexplained (SIDS). Of the 220 control families, 194 (88\%) follow-up interviews were conducted. We had analysable hearing data for 24 SIDS infants (40\%) and 98 controls (51\%). Results OAE signals were marginally increased rather than decreased among SIDS infants for the right ear, especially at lower frequencies, but not significantly so. The strongest predictors of SIDS were bed-sharing in hazardous (infant sleeping next to a carer who smoked, drank alcohol or slept on a sofa) circumstances ( $35 \%$ vs $3 \%$ controls, $p<0.0001$ ), infants found prone ( $33 \%$ vs $3 \%$ controls, $p<0.0001$ ) and infants whose health in the final week was 'not good' ( $53 \%$ vs $9 \%$ controls, $p<0.0001$ ). The prevalence of maternal smoking during pregnancy among both SIDS mothers (20\%) and controls $(10 \%)$ was much lower than previous studies.

Conclusions Hearing data were difficult to obtain; larger numbers would be needed to determine if asymmetrical differences between the right and left ear were a marker for SIDS. A national prospective registry for monitoring and a renewed campaign to a new generation of parents needs to be considered underlining the initial message to place infants on their backs for sleep and the more recent message to avoid bed-sharing in hazardous circumstances.

\section{INTRODUCTION}

Despite its reduced incidence, sudden infant death syndrome (SIDS) is the second leading cause of postneonatal infant mortality in
Strengths and limitations of this study

- This study uses routinely collected hearing data to test a novel hypothesis.

- This study also collects valuable data from bereaved parents to monitor sudden infant death syndrome risk factors.

- The retrospective nature of the study (collecting data from bereaved families over a 10-year period) limits the generalisability of the findings and leaves it open to recall bias.

- Difficulties in collecting routine hearing data hinder interpretation of the findings.

England and Wales, ${ }^{1}$ the highest among infants of younger mothers ${ }^{2}$ and common in socially deprived families. ${ }^{3}$ Epidemiological markers at birth are available to identify some families at increased risk ${ }^{4}$ but are neither sensitive nor specific enough to make targeted intervention possible. ${ }^{5}$ A physiological marker independent of current demographic identifiers would have the potential for making targeted intervention viable.

In 2008, a study demonstrated an altered newborn otoacoustic emission (OAE) hearing test in 31 infants who subsequently died of SIDS compared with 31 control infants. ${ }^{6}$ The OAE is the sound signal generated by the cochlea as a response to sound and recorded in the ear canal. This observation begs the question-are altered OAEs a marker of predisposition to SIDS? If so, can the newborn OAE hearing test be used in combination with epidemiological markers to identify 'at-risk' infants at birth? However, maternal smoking during pregnancy was not measured in the Rhode Island Study, so it could be that exposure to tobacco smoke in 
utero resulted in developmental differences associated with infant hearing which would confound the potential of an improved screening tool but would still add to our understanding of causal mechanisms for some of these deaths. Most infants ( $>99 \%)$ in England have a hearing test shortly after birth and the data, stored by Public Health England since 2010, could be suitable for analysis.

In England and Wales, SIDS deaths have fallen from a peak of nearly 1600 deaths in $1988^{7}$ to just over 200 deaths in 2016. ${ }^{2}$ Longitudinal data collected in Avon suggest not only that there has been a shift towards poorer families but that prone positioning is still a feature of these deaths ${ }^{3}$ and bed-sharing in hazardous conditions (next to a parent who has consumed alcohol, drugs or regularly smokes or uses an unsafe sleeping surface such as a sofa) has emerged as a highly significant risk factor. ${ }^{48}$

We conducted a retrospective case-control study of SIDS infants and surviving controls primarily to investigate whether decreased OAE signal recordings in the right ear are associated with an increased risk of SIDS, and secondarily to investigate any recent changes in epidemiological characteristics.

\section{METHODOLOGY}

\section{Governance}

We used the Strengthening the Reporting of Observational Studies in Epidemiology case-control checklist when writing our report. ${ }^{9}$

\section{Patient and public involvement}

We work closely with bereaved parents who encourage us to collect detailed observational data to both further our understanding of causal mechanisms and provide evidence for risk reduction advice. For this study families were recruited retrospectively via The Lullaby Trust (the main SIDS charity in England https://www.lullabytrust.org.uk/). As with our previous studies, the bereaved families involved in this study will be the first to receive the findings before wider dissemination is made in publications and scientific conferences largely organised by bereaved parent groups.

\section{Recruitment of cases}

A request was sent for families to contact The Lullaby Trust if they had experienced an unexpected death of an infant or child up to and including the age of 3 years since 2008. Data on children who died from 1 to 3 years old will be reported separately.

Families who responded to this request were given a brief written and verbal explanation of what the study involved by the trust as well as being asked to agree to be contacted by the research team. The subsequent telephone interview was conducted by one of the clinical members of the team using a semistructured questionnaire format. On receipt of signed consent forms, we wrote to the relevant coroners' offices to request copies of all inquest documentation, including (but not limited to) the police report, sudden unexpected deaths in infancy (SUDI) paediatrician report and postmortem report. We then conducted multiprofessional case review meetings to categorise each case according to the Avon clinicopathological system ${ }^{10}$ as an explained or unexplained (SIDS) death.

\section{Recruitment of controls}

We recruited controls from St Michael's Hospital, Bristol and Birmingham Women's Hospital from June 2016 to August 2017 inclusive. Mothers who had given birth to infants at or after 35 weeks' gestation who had no significant medical problems were approached by one of the research team within 24 hours of delivery. Participants were interviewed by telephone using the same semistructured interview to obtain information about a reference infant sleep within 24 hours of the call, when their infants were at similar ages to the anticipated ages of death of the index infants. We tried to distribute the times and days of the week for the reference sleep to match as closely as possible those on which the deaths had occurred.

\section{Collection of hearing data}

The hearing data obtained depended on the screening equipment being used. Two different recording systems are used within the National Health Service to collect infant hearing data which are stored by a private company contracted to Public Health England. The systems are Otoport (Otodynamics, Hatfield, UK) system and Accuscreen (Madsen from Natus, formerly GN Otometrics, Copenhagen, Denmark). The Otodynamics system collects signal and noise recordings (as in the early US study) for both the right and left ear at five frequencies $(1 \mathrm{kHz}, 1.5 \mathrm{kHz}, 2 \mathrm{kHz}, 3 \mathrm{kHz}$ and $4 \mathrm{kHz})$ with the signal generally improving the higher the frequency. The Otodynamics recordings included signal and noise measured in decibels $(\mathrm{dB})$ and provided as logarithms, so the ratio is calculated as noise subtracted from the signal. A measure (\%) of confidence in the reliability of the recording is also given. There is debate as to whether signal to noise ratio or just signal would be the best measure, so we have provided both. The data were extracted using the Otodynamics ILO Data Explorer. The Accuscreen device also provides data for both right and left ear but is more limited as the OAE result at the different frequencies are combined. The only useful measurement related to the strength of the OAE signal from these recordings appears to be the length of time it took to get a positive response (a total of eight valid peaks in alternating direction of the OAE waveform has been achieved to formulate a 'pass' for the test). The Accuscreen recordings included the duration to achieve a positive response (in seconds), the artefact rate (related to noise) which should below $20 \%$ if possible, the stimulus stability (emanating from the probe stability) which should be above $80 \%$ if possible and the probe fit which is also measured as a $\%$ in terms of how successfully it was fitted. These data were extracted using the Madsen Acculink package. 
Table 1 Avon classification of sudden unexpected deaths in infancy*

\begin{tabular}{|c|c|c|c|}
\hline 0 & Information not collected & $0 / 64$ & $0 \%$ \\
\hline $\mathrm{IA}$ & No potentially significant factors or contributory factors found (SIDS) & $0 / 64$ & $0 \%$ \\
\hline IB & Factors present but not likely to have contributed to the death (SIDS) & $10 / 64$ & $15.6 \%$ \\
\hline IIB & Factors present and probably contributed to the death (SIDS) & $21 / 64$ & $32.8 \%$ \\
\hline III & Fully explained death & $4 / 64$ & $6.3 \%$ \\
\hline
\end{tabular}

*The multiprofessional case review meetings included a range of relevant professionals with experience in the field (paediatrician, paediatric pathologist, health visitor, police officer, social worker). After discussion of each case, each was categorised according to the Avon clinicopathological categorisation system ${ }^{8}$ as an explained or unexplained (SIDS) death.

SIDS, sudden infant death syndrome.

\section{Statistical methodology}

The univariable and multivariable analyses were calculated using logistic regression in SPSS Version 24. Medians and IQRs were used to describe continuous data that were not normally distributed and comparisons tested using the Mann-Whitney U test. Categorical data were tested using $\mathrm{X}^{2}$. Given the expected relatively low number of SIDS cases, multivariate adjustments were limited to essential covariates and simple dichotomies were used for multicategorical and continuous variables. Variable selection used the backward stepwise selection method and any variable with more than $10 \%$ data missing was modelled separately in a sensitivity analysis.

\section{RESULTS}

\section{Ascertainment}

Of 102 bereaved families who contacted The Lullaby Trust, we completed the interviews with the families of 91 children who died suddenly and unexpectedly. There were 27 deaths between the ages of 1 and 3 years (SUDC) which will be reported separately and 64 were SUDI. Four unexpected infant deaths were fully explained: two from previously unrecognised cardiac abnormalities, and two from acute infections. For 50/60 SIDS deaths (83\%), the multiagency review process identified possible or probable contributory factors that could not in themselves fully explain the death (table 1 ).

Of the 220 control families who consented to take part in the maternity hospital, $194(88 \%)$ completed a follow-up telephone interview (79 from Bristol and 115 from Birmingham). The 26 control families lost to follow-up were more likely to have preterm infants $(<37$ weeks: $7.7 \%$ vs $1.5 \%, \mathrm{p}=0.08$ ) and a greater proportion of mothers with lower educational achievements (highest qualification $\leq$ General Certificate of Secondary Education or equivalent: $36 \%$ vs $16.5 \%, \mathrm{p}=0.02$ ) but there were no major differences in gender, ethnicity, maternal smoking during pregnancy, maternal age, number of siblings or birth weight.

\section{Temporal weighting}

The 60 SIDS deaths occurred between 2007 and 2017 with no marked seasonal difference. The reference sleep of the controls occurred between June 2016 and August 2017 inclusive with an increased number in the coldest quarter of December, January and February (25\% SIDS deaths vs $60 \%$ controls, $\mathrm{p}<0.0001)$. As figure 1 shows, the median age of the SIDS infants was 85 days (IQR: 49-159 days), the median age of the control infants in this study was 77 days (IQR: 44-114 days). The slight difference in age distribution was not statistically significantly (MannWhitney U test: $\mathrm{p}=0.18$ ). Of the 60 SIDS deaths 58 occurred while the infant was thought by the parents to be asleep; $17 / 58$ (29.3\%) deaths occurred during what the parents considered to be a daytime sleep, significantly more than the daytime reference sleeps of control infants (26/194 or $13.4 \%, \mathrm{p}=0.007)$. There was no significant variation in the number of deaths or of reference sleeps by day of the week. (Mann-Whitney U test: $\mathrm{p}=0.97$ ) (figure 2).

\section{Demographic characteristics}

Table 2 compares the background and perinatal demographics of the SIDS infants and controls. There was a slight preponderance of males and a higher proportion with white ethnicity among the SIDS infants. Lower levels of maternal educational achievement were more prevalent among the SIDS families; highest educational attainment was either below or no more than the standard expected at 16 years old for half of the SIDS mothers (three times more than control mothers). The SIDS mothers were slightly younger (median age 29 years (IQR: 26-33 years)) than the control mothers (median age 31 years (IQR: 28-34 years)), but this difference was not significant.

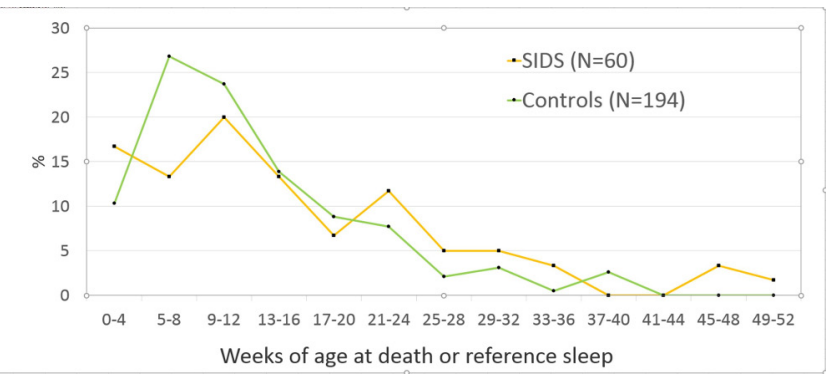

Figure 1 Age at death or reference sleep (SIDS vs controls). SIDS, sudden infant death syndrome. 


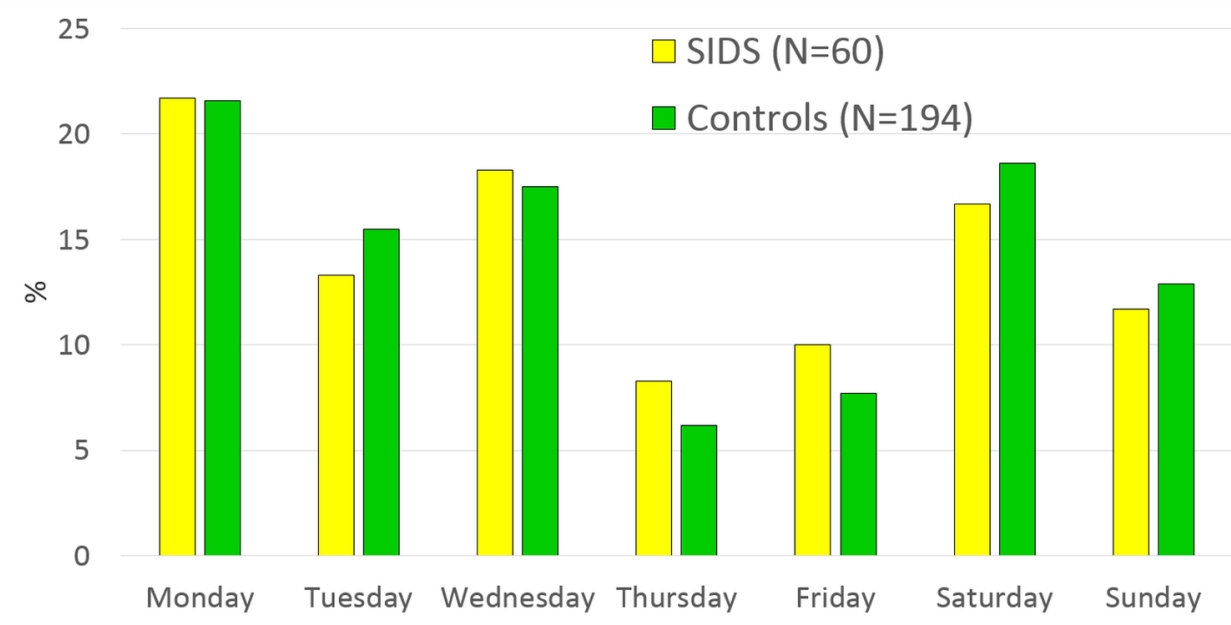

Day of week of death or reference sleep

Figure 2 Day of week of death or reference sleep (SIDS vs controls). SIDS, sudden infant death syndrome.

\section{Hearing data}

Hearing screening tests were conducted for all but one of the SIDS cases and all the controls although analysable records were only available for $60 \%$ of the SIDS infants and $91 \%$ of the controls. For the SIDS infants lack of written consent $(15 \%)$, missing records post-2010 $(8 \%)$, unusable records pre-2010 (5\%) and no clear OAE response $(12 \%)$ explain the lack of availability. Among the controls, there was no clear OAE response for $17 / 194$ infants $(9 \%)$.

We had Accuscreen hearing records for the right and left ear available for 12 SIDS infants and 79 controls. The median duration of the test recording that was required to achieve a pass in the right ear was slightly shorter among the SIDS infants (20s) compared with the controls (23s) but not significantly different (table 3 ). The median duration of the test recording was shorter for both groups in the left ear but significantly so for the SIDS infants (10.5 s) compared with the controls (16s). There were no significant differences observed between SIDS infants and controls in artefact rate, stimulus stability or probe fit.

We had Otodynamics hearing records for the right and left ear available for 24 SIDS infants and 98 controls. Table 4 compares the median signal, noise, signal to noise

Table 2 Demographic characteristics (SIDS vs controls)

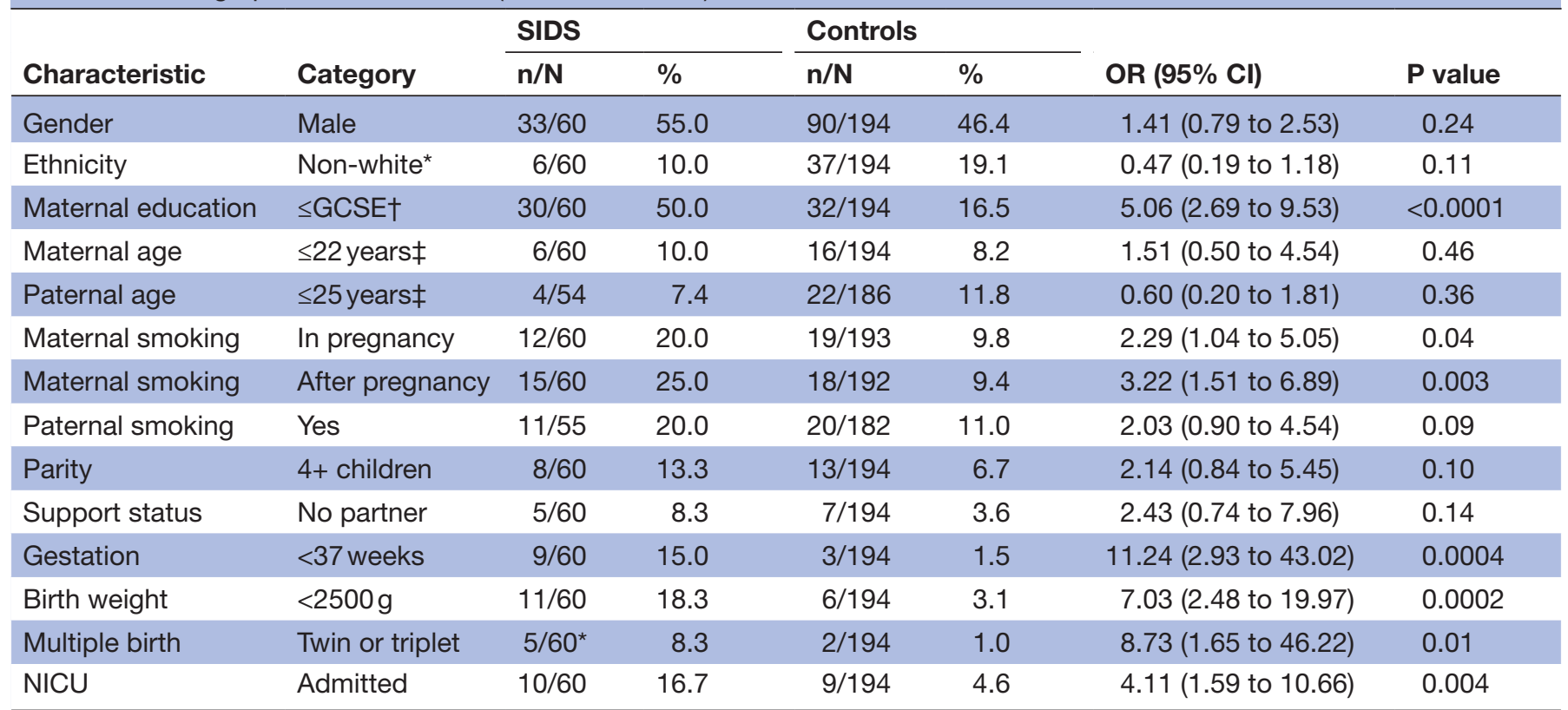

*SIDS (3 mixed race, 2 Asian, 1 black), Controls (21 mixed race, 10 Asian, 4 black, 2 other). †Highest educational qualification of mother was the General Certificate of Secondary Education (GCSE) (awarded at 16 years) or below. $\ddagger$ Cut-off based on $10 \%$ youngest of the age distribution from all the data.

NICU, neonatal intensive care unit; SIDS, sudden infant death syndrome. 
Table 3 Accuscreen recordings in the right and left ear (SIDS vs controls)

\begin{tabular}{|c|c|c|c|c|c|c|}
\hline & \multirow[b]{2}{*}{ Unit } & \multicolumn{2}{|c|}{ SIDS } & \multicolumn{2}{|c|}{ Controls } & \multirow[b]{2}{*}{$P$ value } \\
\hline & & $\mathbf{N}$ & Median (IQR) & $\mathbf{N}$ & Median (IQR) & \\
\hline \multicolumn{7}{|l|}{ Right ear } \\
\hline Artefact rate* & $\%$ & 11 & $2(0-13)$ & 75 & $7(1-19)$ & 0.36 \\
\hline Stimulus stability $\dagger$ & $\%$ & 11 & $100(100-100)$ & 75 & $100(100-100)$ & 0.62 \\
\hline \multicolumn{7}{|l|}{ Left ear } \\
\hline Duration & Seconds & 12 & $10.5(6.75-15.5)$ & 77 & $16(11-38)$ & 0.03 \\
\hline Artefact rate $\neq$ & $\%$ & 11 & $0(0-29)$ & 74 & $4(0-17)$ & 0.40 \\
\hline Stimulus stability§ & $\%$ & 11 & $100(100-100)$ & 74 & $100(100-100)$ & 0.23 \\
\hline Probe fit & $\%$ & 8 & $42(20.5-72.25)$ & 74 & $44(33.75-54)$ & 0.42 \\
\hline
\end{tabular}

${ }^{*}$ Artefact rate $<20 \%$ in $2 / 11$ (18.2\%) SIDS and $17 / 75$ (22.7\%) controls $(p=0.74)$.

†Stimulus stability $>80 \%$ in all 11 SIDS and $72 / 75(96 \%)$ controls.

$\ddagger$ Artefact rate $<20 \%$ in $3 / 11(27.3 \%)$ SIDS and $13 / 74(17.6 \%)$ controls $(p=0.45)$.

§Stimulus stability $>80 \%$ in all 11 SIDS and $71 / 74$ (95.9\%) controls.

SIDS, sudden infant death syndrome.

ratio and confidence (in percentage terms) of these findings between SIDS and controls in the right and left ear. The median signal in the right ear was slightly higher among the control infants at $1 \mathrm{kHz}$ and $2 \mathrm{kHz}$ frequency and slightly higher among the SIDS infants at $1.5 \mathrm{kHz}$, $3 \mathrm{kHz}$ and $4 \mathrm{kHz}$ frequencies but none of these differences were statistically significant. The signal to noise ratio in the right ear was consistently slightly higher among the SIDS infants compared with the controls but again none of these differences were statistically significant. At $2 \mathrm{kHz}$, $3 \mathrm{kHz}$ and $4 \mathrm{kHz}$, this difference increased with frequency $(0.15 \mathrm{~dB}, 1.45 \mathrm{~dB}$ and $2.55 \mathrm{~dB})$. The median signal in the left ear was significantly higher among the control infants at $1 \mathrm{kHz}(\mathrm{p}=0.004)$, although within the equipment noise floor, higher (but not significantly so) at $1.5 \mathrm{kHz}$ ( $\mathrm{p}=0.33$ ) and at $2 \mathrm{kHz}(\mathrm{p}=0.63)$, conversely the median signal was slightly higher among the SIDS infants at $3 \mathrm{kHz}(\mathrm{p}=0.23)$ and $4 \mathrm{kHz}(\mathrm{p}=0.25)$. The noise was also significantly higher among the control infants at $1 \mathrm{kHz}(\mathrm{p}=0.023)$ and almost significant at $1.5 \mathrm{kHz}(\mathrm{p}=0.06)$. Subtracting the signal in the right ear from the left ear to look at right/left asymmetry (figure 3 ) the right ear was more dominant among the SIDS infants at all frequencies but particularly for the lower frequencies, although this was not significant and the confidence score at these lower frequencies was quite low.

\section{Multivariable risk factors}

Table 5 lists those factors that remained significant in the multivariable analysis when adjusted for infant age and the other factors in the model. The highest risk was associated with those infants sleeping next to a carer who had consumed alcohol, smoked tobacco or was sleeping on a sofa (35\% vs $3 \%$ controls). In this study, $8 / 60$ SIDS infants were found cosleeping on a sofa compared with 1/194 control infants. Infants being found prone exhibited a strong association; notably, for all six control infants found in this position this was the usual positioning and only one was younger than 3 months of age; in contrast for nearly two-thirds of the SIDS infants found prone (10 out of the 16 who responded) this was not the usual position found and 9 of these 20 infants were aged less than 3 months. Fewer Infants were put down in the prone position although this was more common among the SIDS infants and significant ( $11 \%$ vs $1.6 \%$ controls, $\mathrm{p}=0.004$ ); only three SIDS infants (5.7\%) were placed on their side and all three were found on their side, a similar proportion to the controls $(7.3 \%)$.

In the final week before the last sleep over half the SIDS infants were described by the carer as having health that was only fair or poor (rather than good) and one-third were reported to have fed less than usual compared with a smaller proportion for both these factors among the controls (11\% and $6 \%$, respectively). Being a twin and having a less well-educated mother were the two strongest demographic characteristics of SIDS infants.

Maternal smoking during pregnancy was notable for its absence in the final model, mainly because of the low prevalence both among the SIDS mothers (20\%) and controls $(10 \%)$. More of the SIDS infants used a dummy for the last sleep but this was not significant ( $40 \%$ vs $35 \%$ controls, $\mathrm{p}=0.50$ ). Only around a quarter of the SIDS carers who provided a dummy could recall what happened during the final infant sleep and five of the six carers responded that the dummy fell out or was removed soon after the infant fell asleep. Among the controls, nearly all $(61 / 65$ or $94 \%)$ thought the dummy fell out or was removed soon after sleep onset. More of the control infants used an infant sleeping bag for the last sleep but this did not reach univariable significance (22\% SIDS vs $36 \%$ controls, $\mathrm{p}=0.06$ ) 
Table 4 Otodynamics recordings for the right and left ear (SIDS vs controls)

\begin{tabular}{|c|c|c|c|c|}
\hline \multirow[b]{2}{*}{ Frequency } & \multirow[b]{2}{*}{ Measure } & \multirow{2}{*}{$\begin{array}{l}\text { SIDS (n=24) } \\
\text { Median (IQR) }\end{array}$} & \multirow{2}{*}{$\begin{array}{l}\text { Controls (n=98) } \\
\text { Median (IQR) }\end{array}$} & \multirow[b]{2}{*}{$P$ value* } \\
\hline & & & & \\
\hline \multicolumn{5}{|l|}{ Right ear } \\
\hline \multirow[t]{4}{*}{$1 \mathrm{kHz}$} & Signal & $-2.70(-9.65$ to +6.35$)$ & $-1.40(-6.43$ to +5.23$)$ & 0.62 \\
\hline & Noise & $+7.70(+1.20$ to +11.08$)$ & $+7.05(+1.80$ to +12.43$)$ & 0.47 \\
\hline & SNR & $-7.75(-12.98$ to -2.60$)$ & $-8.00(-13.63$ to -1.30$)$ & 0.93 \\
\hline & Confidence & $14.5 \%(5.0 \%$ to $35.0 \%)$ & $14.0 \%(4.0 \%$ to $43.0 \%)$ & 0.90 \\
\hline \multirow[t]{4}{*}{$1.5 \mathrm{kHz}$} & Signal & +9.30 (+5.98 to +14.08) & +8.45 (+2.28 to +11.00) & 0.25 \\
\hline & Noise & $+6.80(-0.08$ to +11.05$)$ & $+6.60(+2.38$ to +12.38$)$ & 0.91 \\
\hline & SNR & $+2.45(-0.63$ to +8.80$)$ & $+0.55(-3.85$ to +4.70$)$ & 0.16 \\
\hline & Confidence & $63.5 \%(46.5 \%$ to $88.5 \%)$ & $53.5 \%(29.0 \%$ to $74.25 \%)$ & 0.15 \\
\hline \multirow[t]{4}{*}{$2 \mathrm{kHz}$} & Signal & +11.25 (+8.75 to+15.63) & +12.10 (+7.43 to 16.50$)$ & 0.92 \\
\hline & Noise & $+4.25(-1.40$ to +8.08$)$ & $+4.15(-0.90$ to +7.83$)$ & 0.85 \\
\hline & SNR & $+7.25(+4.83$ to +14.73$)$ & $+7.10(+3.85$ to +11.33$)$ & 0.71 \\
\hline & Confidence & $84.0 \%(75.0 \%$ to $96.25 \%)$ & $84.0 \%(70.75 \%$ to $93.0 \%)$ & 0.72 \\
\hline \multirow[t]{4}{*}{$3 \mathrm{kHz}$} & Signal & +17.15 (+12.53 to +20.58) & $+15.00(+0.18$ to +20.38$)$ & 0.26 \\
\hline & Noise & $+6.00(+1.73$ to +8.50$)$ & $+4.20(+1.75$ to +7.90$)$ & 0.56 \\
\hline & SNR & $+9.50(+6.73$ to +17.10$)$ & $+8.05(+6.40$ to +12.45$)$ & 0.29 \\
\hline & Confidence & $90.0 \%(82.75 \%$ to $97.75 \%)$ & $86.0 \%(82.0 \%$ to $94.25 \%)$ & 0.27 \\
\hline \multirow[t]{4}{*}{$4 \mathrm{kHz}$} & Signal & $+13.00(+7.98$ to +20.43$)$ & +11.05 (+6.40 to +16.33) & 0.20 \\
\hline & Noise & $+2.25(-1.75$ to +4.68$)$ & $+0.50(-2.43$ to +3.68$)$ & 0.35 \\
\hline & SNR & $+12.40(+7.78$ to +17.20$)$ & +9.85 (+6.28 to +15.00) & 0.18 \\
\hline & Confidence & $94.5 \%(85.25 \%$ to $98.0 \%)$ & $90.5 \%(81.0 \%$ to $97.0 \%)$ & 0.20 \\
\hline \multicolumn{5}{|l|}{ Left ear } \\
\hline \multirow[t]{4}{*}{$1 \mathrm{kHz}$} & Signal & $-6.95(-12.20$ to +0.43$)$ & $-0.10(-5.43$ to +5.40$)$ & 0.004 \\
\hline & Noise & $+2.70(+0.55$ to +6.28$)$ & $+6.35(+0.50$ to +11.13$)$ & 0.023 \\
\hline & SNR & $-8.55(-12.23$ to -1.90$)$ & $-4.35(-10.70$ to +0.63$)$ & 0.11 \\
\hline & Confidence & $12.5 \%(5.25 \%$ to $39.5 \%)$ & $27.0 \%(8.5 \%$ to $53.25 \%)$ & 0.10 \\
\hline \multirow[t]{4}{*}{$1.5 \mathrm{kHz}$} & Signal & $+5.50(+3.58$ to +10.73$)$ & +8.05 (+3.98 to +11.00) & 0.33 \\
\hline & Noise & $+3.40(+0.75$ to +9.00$)$ & $+6.90(+2.93$ to +10.83$)$ & 0.06 \\
\hline & SNR & $+3.20(-2.60$ to +6.38$)$ & $+1.75(-2.65$ to +5.53$)$ & 0.54 \\
\hline & Confidence & $67.5 \%(35.25 \%$ to $81.0 \%)$ & $60.0 \%(34.75 \%$ to $78.5 \%)$ & 0.15 \\
\hline \multirow[t]{4}{*}{$2 \mathrm{kHz}$} & Signal & +9.25 (+4.93 to +16.78) & +11.10 (+7.38 to 14.80$)$ & 0.63 \\
\hline & Noise & $+2.40(-2.65$ to +4.53$)$ & $+2.05(-0.53$ to +6.10$)$ & 0.50 \\
\hline & SNR & $+7.90(+4.43$ to +12.28$)$ & $+7.10(+4.55$ to +13.23$)$ & 0.79 \\
\hline & Confidence & $86.0 \%(73.0 \%$ to $94.5 \%)$ & $84.00(73.75 \%$ to $95.0 \%)$ & 0.80 \\
\hline \multirow[t]{4}{*}{$3 \mathrm{kHz}$} & Signal & $+16.35(+10.35$ to +20.33$)$ & $+13.30(+8.95$ to +18.30$)$ & 0.23 \\
\hline & Noise & $+3.20(+0.78$ to +4.70$)$ & $+2.45(-0.13$ to +5.53$)$ & 0.53 \\
\hline & SNR & +11.25 (+6.89 to +17.65) & $+9.55(+6.30$ to +14.50$)$ & 0.28 \\
\hline & Confidence & $93.0 \%(82.75 \%$ to $98.0 \%)$ & $90.0 \%(81.0 \%$ to $96.25 \%)$ & 0.31 \\
\hline \multirow[t]{4}{*}{$4 \mathrm{kHz}$} & Signal & +14.20 (+6.53 to +17.28) & $+10.70(+5.73$ to +15.63$)$ & 0.25 \\
\hline & Noise & $-0.70(-2.35$ to +2.80$)$ & $-0.75(-3.00$ to +2.43$)$ & 0.74 \\
\hline & SNR & +12.45 (+6.78 to +16.50) & +10.80 (+6.20 to +15.40) & 0.38 \\
\hline & Confidence & $94.5 \%(82.75 \%$ to $98.0 \%)$ & $92.5 \%(81.0 \%$ to $97.0 \%)$ & 0.42 \\
\hline
\end{tabular}

Signal, noise and SNR measured in $\mathrm{dB}$.

*Mann-Whitney U test.

SIDS, sudden infant death syndrome; SNR, signal to noise ratio. 


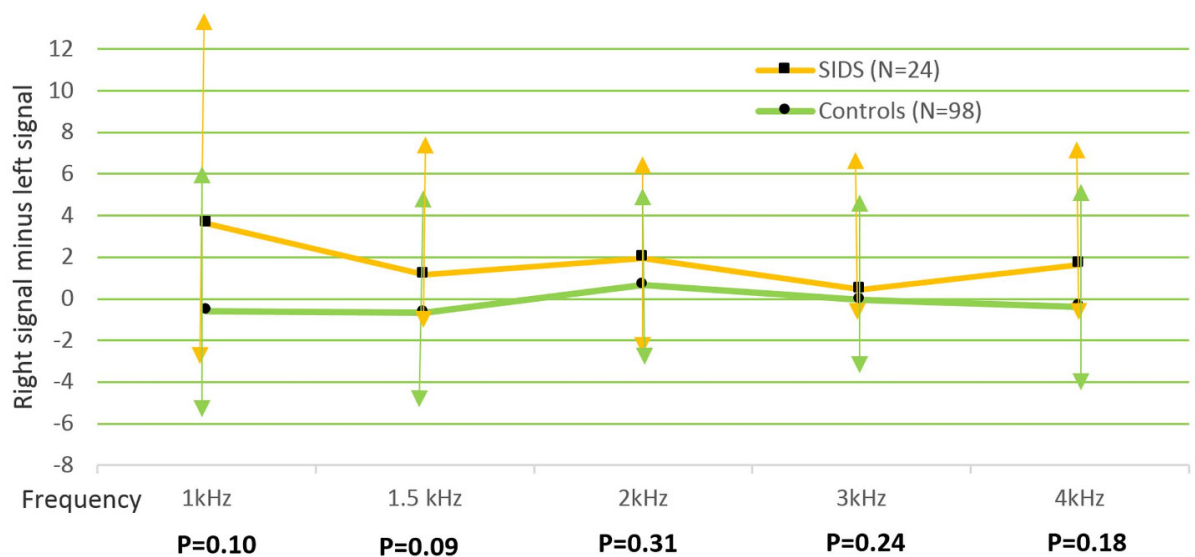

Figure 3 Comparison of individual right/left ear symmetry of signal (SIDS vs controls) median difference and IQR. SIDS, sudden infant death syndrome.

\section{DISCUSSION}

We were not able to confirm the promising findings on OAE from the previous study. ${ }^{6}$ In that study, the signal to noise ratio was consistently and significantly $4 \mathrm{~dB}$ lower at $2 \mathrm{kHz}, 3 \mathrm{kHz}$ and $4 \mathrm{kHz}$ in the right ear of infants who subsequently went on to die of SIDS compared with surviving controls. In our study, the difference in signal to noise ratio was in the opposite direction; higher in the right ear of SIDS infants than controls and this difference increased (from 0.15 to $2.55 \mathrm{~dB}$ ) the higher the frequency although this was not statistically significant. There were potential asymmetrical differences between the SIDS infants and controls at lower frequencies but the low confidence in these scores and small numbers requires cautious interpretation.

The right ear advantage in cochlear function has been well described in infants, with right OAEs approximately $1 \mathrm{~dB}$ larger than left. ${ }^{11-13}$ This interaural asymmetry is hypothesised to reflect developmental differences in the activity of the medial olivocochlear efferent system between the ears ${ }^{14}{ }^{15}$; differences in ear asymmetry between SIDS and control infants could indicate developmental differences in early auditory efferent function.
The major limitation is that both studies were underpowered. A larger study would be needed to detect any subtle differences in infant hearing should such differences genuinely exist. Accessing hearing data in the UK was difficult; we encountered delays, missing records, inability for the contracted company to read the data they store and monitoring systems that were incompatible.

As with our study conducted 10 years ago, ${ }^{4}$ just over half the SIDS infants were found next to a carer and bed-sharing in hazardous circumstances was the strongest association with SIDS in the multivariable model. Initiatives to highlight the specific hazards to parents who bed-share and clearly explain the evidence to health professionals such as the Unicef 'Caring for your baby at night' leaflets ${ }^{16}$ and 'Cosleeping and SIDS' infographic ${ }^{17}$ need to be encouraged. The proportion of SIDS infants found prone seems stubbornly persistent over the years; $38 \%$ in our study 20 years ago, ${ }^{18} 29 \%$ in our study 10 years ago $^{4}$ and $33 \%$ in our current study. Although the proportion found prone in the control population was low, our studies of high-risk families in socioeconomically deprived areas in Bristol suggest that parental awareness of this risk factor was poor (only a half of the 400 mothers surveyed

Table 5 Multivariable model (SIDS vs controls)

\begin{tabular}{|c|c|c|c|c|c|c|c|}
\hline \multirow[b]{2}{*}{ Characteristic } & \multirow[b]{2}{*}{ Category } & \multicolumn{2}{|l|}{ SIDS } & \multicolumn{2}{|c|}{ Controls } & \multirow[b]{2}{*}{ OR (95\% Cl) } & \multirow[b]{2}{*}{$P$ value } \\
\hline & & $\mathrm{n} / \mathrm{N}$ & $\%$ & $\mathrm{n} / \mathrm{N}$ & $\%$ & & \\
\hline Sleeping with carer & Hazardous $\dagger$ & $21 / 60$ & 35.0 & $6 / 194$ & 3.1 & 40.2 (10.6 to 152.8 ) & $<0.0001$ \\
\hline Sleeping position & Found prone & $20 / 60$ & 33.3 & $6 / 194$ & 3.1 & 29.1 (7.2 to 118.0$)$ & $<0.0001$ \\
\hline Health final week & Fair or poor & $32 / 60$ & 53.3 & $18 / 194$ & 9.3 & 10.9 (3.9 to 31.1$)$ & $<0.0001$ \\
\hline Multiple birth & Twin & $5 / 60$ & 8.3 & $2 / 194$ & 1.0 & 57.4 (7.4 to 444.1$)$ & 0.0002 \\
\hline Feeding final week & $<$ Usual & $20 / 60$ & 33.3 & $12 / 194$ & 6.2 & 5.0 (1.5 to 16.7$)$ & 0.009 \\
\hline Maternal education & $\leq$ GCSE $\ddagger$ & $30 / 60$ & 50.0 & $32 / 194$ & 16.5 & 3.9 (1.4 to 11.0$)$ & 0.01 \\
\hline
\end{tabular}

*Adjusted for infant age, 60 SIDS cases and 194 controls in the model.

†Includes those sleeping directly next to a parent that has consumed alcohol or smoked or where carer or infant slept on a sofa.

łHighest educational qualification of mother was the General Certificate of Secondary Education (GCSE) (awarded at 16 years) or below.

SIDS, sudden infant death syndrome. 
in 2014 identified avoiding prone sleep position as one of the top three risk reduction strategies for SIDS). ${ }^{19}$

Our three studies conducted in England show that the prevalence of maternal smoking during pregnancy has fallen from $27 \% 20$ years ago ${ }^{20}$ to $14 \% 10$ years ago ${ }^{5}$ to $10 \%$ in this study reflecting a national trend. Among the SIDS families, the prevalence in these three studies has fallen from $66 \%$ to $59 \%$ and just $20 \%$ in the current study. This may be a consequence of a reduced population prevalence but may partly be explained by the bias towards less deprived and more articulate families who volunteered to take part in this study compared with the families in our previous prospective population-based studies.

As well as using a retrospective design and a relatively small sample, there were other limitations to this study. Most of the SIDS deaths occurred between 2010 and 2017; during this period, there were over 2000 SIDS deaths in England suggesting our self-selected SIDS sample was around $3 \%$ of the SIDS population which may not be representative of the wider English population. The potential for recall bias was high especially regarding specific details of the final sleep such as response to what happened to the infant dummy which was only recollected by a quarter of the SIDS parents compared with virtually all the controls. The data from the controls were prospectively collected but recruitment was opportunistic and access to the more vulnerable infants was difficult, yielding a control population with fewer premature and low birthweight infants than the national average. We were not able to arrange control interviews that would reflect the seasonal distribution of SIDS deaths or reflect the higher than expected proportion of daytime deaths, and telephone interviews are a poor substitute for faceto-face ones.

Many of the families with whom we spoke were under the impression that the information they had already given to the healthcare staff or the police after their child's death were available to be used for research, and many expressed surprise and anger when informed this was not the case. All but one bereaved family told us that, had they been asked at the time of their child's death, they would have given permission for the data and the pathology samples to be used in future research projects aimed at preventing such deaths. This information has led us to propose the establishment of a national registry of unexpected infant and childhood deaths, to which families could opt in soon after the death of their child, and which would thus have written informed consent to make available the routinely collected information and pathology samples.

We conclude that if routinely collected data are to be fully used for both national monitoring and efficiently designed research investigations, then bodies such as Public Health England need to consider single or compatible monitoring systems that can provide easy access to analysable data, as well as a routine quality control of recorded and stored data. For parents, there need to be renewed efforts to underline the need to place infants on their backs for sleep and avoid bed-sharing in hazardous circumstances.

\section{Author affiliations}

${ }^{1}$ Bristol Medical School, University of Bristol, Bristol, UK

${ }^{2}$ Department of Pediatrics, Seattle Children's Hospital, Seattle, Washington, USA

${ }^{3}$ Department of Research \& Development, Birmingham Women's Hospital,

Birmingham, UK

${ }^{4}$ Institute of Metabolism and Systems Research, University of Birmingham,

Birmingham, UK

${ }^{5}$ Department of Oncology and Metabolism, University of Sheffield, Sheffield, UK

${ }^{6}$ Department of Child Health, University of Warwick Warwick Medical School, Coventry, UK

${ }^{7}$ Institute of Health and Society, Newcastle University, Newcastle upon Tyne, UK

${ }^{8}$ Department of Pathology, University of Sheffield, Sheffield, UK

${ }^{9}$ Department of Audiology, Imperial College London, London, UK

${ }^{10}$ National Institute of Health Research Clinical Research Network: West of England, University of Bristol, Bristol, UK

Acknowledgements We would like to thank Francine Bates, Lucy Lyus and Jenny Ward at the Lullaby Trust for helping with recruitment, Siobhan Ryan at Public Health England for helping obtain the hearing records, Mark Cook at Northgate Public Services for his assistance with sending the data, Abhilash Vora for data entry and cleaning and most of all the parents who have provided information for this study that may help future parents.

Contributors DR, PF, PSB, AP and Jl were responsible for developing the research question. PF, DR, PSB, JI, AP, AH, DM, AKE and AD were responsible for the study design. PF, AP, PS, MCC, MWP and RC were responsible for data collection, death classification and quality assessment of the investigation into the death. AP was responsible for study management. PSB initially drafted the paper. All authors read, commented on and approved the final manuscript.

Funding This work was supported by The Lullaby Trust (project number 268) with funding also received from Teddy's Wish and Seattle Children's Hospital.

Disclaimer These sponsors had no role in the study design; in the collection, analysis and interpretation of the data; in the writing of the report; or in the decision to submit the paper for publication.

Competing interests None declared.

Patient consent for publication Not required.

Ethics approval Ethical approval was sought and gained from the South West Central Bristol Research Ethics Committee; REC (reference: 14/SW/1084). The date of approval was 22 March 2016.

Provenance and peer review Not commissioned; externally peer reviewed.

Data sharing statement The data we have collected are sensitive and include information from bereaved parents and coroner's reports. We are happy to comply with University of Bristol regulations in this matter although it must be understood that ethical approval would be a prerequisite to access.

Open access This is an open access article distributed in accordance with the Creative Commons Attribution Non Commercial (CC BY-NC 4.0) license, which permits others to distribute, remix, adapt, build upon this work non-commercially, and license their derivative works on different terms, provided the original work is properly cited, appropriate credit is given, any changes made indicated, and the use is non-commercial. See: http://creativecommons.org/licenses/by-nc/4.0/.

\section{REFERENCES}

1. Office for National Statistics. Child mortality in England \& Wales 2016. Table 6. Released March 2018. https://www.ons.gov.uk/peop lepopulationandcommunity/birthsdeathsandmarriages/deaths/ datasets/childmortalitystatisticschildhoodinfantandperinatalchild hoodinfantandperinatal\%20mortalityinenglandandwales

2. Office for National Statistics. Statistical bulletin: unexplained deaths in infancy, England and Wales: 2016. Released August 2018. https:// www.ons.gov.uk/peoplepopulationandcommunity/birthsdeathsandm arriages/death\%20s/bulletins/unexplaineddeathsininfancyenglan dandwales/2016

3. Blair PS, Sidebotham P, Berry PJ, et al. Major changes in the epidemiology of sudden infant death syndrome: a 20 year 
population based study of all unexpected deaths in infancy. Lancet 2006;367:314-9.

4. Blair PS, Sidebotham P, Evason-Coombe C, et al. Hazardous cosleeping environments and risk factors amenable to change: casecontrol study of SIDS in south west England. BMJ 2009;339:b3666.

5. Fleming PJ, Blair PS, Pease A. Sudden unexpected death in infancy: aetiology, pathophysiology, epidemiology and prevention in 2015. Arch Dis Child 2015;100:984-8.

6. Rubens DD, Vohr BR, Tucker R, et al. Newborn oto-acoustic emission hearing screening tests: preliminary evidence for a marker of susceptibility to SIDS. Early Hum Dev 2008;84:225-9.

7. Gilbert R. The changing epidemiology of SIDS. Arch Dis Child 1994;70:445-9.

8. Blair PS, Sidebotham P, Pease A, et al. Bed-sharing in the absence of hazardous circumstances: is there a risk of sudden infant death syndrome? An analysis from two case-control studies conducted in the UK. PLoS One 2014;9:e107799.

9. von Elm E, Altman DG, Egger M, et al. The Strengthening the Reporting of Observational Studies in Epidemiology (STROBE) statement: guidelines for reporting observational studies. J Clin Epidemiol 2008;61:344-9.

10. Fleming PJ, Blair PS, Sidebotham PD, et al. Investigating sudden unexpected deaths in infancy and childhood and caring for bereaved families: an integrated multiagency approach. BMJ 2004;328:331-4.

11. Kei J, McPherson B, Smyth V, et al. Transient evoked otoacoustic emissions in infants: effects of gender, ear asymmetry and activity status. Audiology 1997;36:61-71.

12. Berninger $E$. Characteristics of normal newborn transient-evoked otoacoustic emissions: ear asymmetries and sex effects. Int $J$ Audiol 2007;46:661-9.
13. Keefe DH, Gorga MP, Jesteadt W, et al. Ear asymmetries in middleear, cochlear, and brainstem responses in human infants. $J$ Acoust Soc Am 2008;123:1504-12.

14. Morlet T, Goforth L, Hood LJ, et al. Development of human cochlear active mechanism asymmetry: involvement of the medial olivocochlear system? Hear Res 1999;137:179.

15. Sininger YS, Condon CG, Hoffman HJ, et al. Transient otoacoustic emissions and auditory brainstem responses in low-risk cohort of newborn and one-month-old infants: assessment of infant auditory system physiology in the prenatal alcohol in SIDS and stillbirth network safe passage study. J Am Acad Audiol 2018;29:748-63.

16. UNICEF Baby Friendly Initiative. Caring for your baby at night. https://www.unicef.org.uk/babyfriendly/baby-friendly-resources/ sleep-and-night-time-resources/caring-for-your-baby-at-night/

17. UNICEF Baby Friendly Initiative. Co-sleeping and SIDS Infographic. A guide for health professionals. https://www.unicef.org.uk/ babyfriendly/baby-friendly-resources/sleep-and-night-timeresources/co-sleeping-and-sids/

18. Blair PS, Platt MW, Smith IJ, et al. Sudden infant death syndrome and sleeping position in pre-term and low birth weight infants: an opportunity for targeted intervention. Arch Dis Child 2006;91:101-6.

19. Pease AS, Blair PS, Ingram J, et al. Mothers' knowledge and attitudes to sudden infant death syndrome risk reduction messages: results from a UK survey. Arch Dis Child 2018;103:33-8.

20. Leach CE, Blair PS, Fleming PJ, et al. Epidemiology of SIDS and explained sudden infant deaths. CESDI SUDI Research Group. Pediatrics 1999;104:e43. 